\title{
IMPROVING PERCEIVED SAFETY IN PUBLIC TRANSPORTATION THROUGH DESIGN
}

\author{
DENIZ DENIZ \\ Izmir University of Economics, Turkey
}

\begin{abstract}
Planning and design decisions are crucial for creating safer and sustainable public transportation alternatives. People who live in cities isolate themselves from facilities of the city because of safety and security issues, which reduce their quality of life. Security issues also create a barrier to a participation in the public life and reduce the liveability of the city. This paper uses specific data derived from the responses to a public transportation survey on the subway in addition to the systematic observations. The study includes 351 respondents and analyses their transportation-related habits and feelings of insecurity through the whole journey in Izmir subway. In this respect, this particular study concludes by creating a spatial model, which includes environment/product/management issues for investigating the importance of safety through public transportation and also for developing sustainable solutions.

Keywords: perceived safety, public transportation, transit environment security, environmental design, design against crime.
\end{abstract}

\section{INTRODUCTION}

Crime prevention through planning and design is a critical research topic in academic writing for many years. It is obvious that crime and perceived safety are extremely related to the spatial and environmental issues. In this case planners, designers, local governments and all related actors must work in collaboration to achieve long term and sustainable solutions. In Turkish literature, "crime" is mostly addressed on a wider scale and focuses on reducing crime rate within the whole city or region, mainly concentrating on mapping of public transportation issues. In these studies, spatial analysis are considered in terms of crime prevention and anti-social behaviour patterns that occur in urban areas related to their administrative features. Thus, improving safety of public transportation through design concept has not been integrated with planning and design issues successfully.

In this context, the method of this study mainly includes investigating the design criteria for public transportation safety on various scales to analyse the needs of users for better solutions. This particular study also considers the interdisciplinary analysis of crime prevention studies including local administrators, designers, and many other decisionmakers. The main purpose of the study is to submit results derived from crucial intersection points of Izmir public transport line in order to create safe and sustainable public transportation solutions. In this regard, the study discusses a new perspective for developing safer public transport and suggests approaches to enhance safety in urban public transport areas with its related environments and components. After specifying design problems and priorities at different scales through the data derived from passenger survey and systematic observations, recommendations have been made by evaluating the results and development tendency.

\section{LITERATURE REVIEW}

In urban areas, feelings of insecurity keep people off the public transportation facilities and related spaces such as, public transit areas, subways, bus stops, etc. According to Allford [1] environmental and social features have been correlated with fear of crime and people who commit criminal acts regularly are people who also have opportunities to break the law. 
Altman and Cheemers emphasize that characteristics of the built environment contribute to crime in public areas and these features can be both physical and social [2]. Cozens mainly defines that areas that are feared are not always areas of high crime and people have a higher perception of the level of crime in some dull or neglected areas. Design and maintenance of public areas can create potential concealment or entrapment places for potential offenders because of poor lighting, isolation and potential escape routes that have an impact on increased fear of crime for users [3]. It is also crucial to find out how design decisions have been made in response to particular local needs.

Since the community ownership of public spaces send positive signals to the community, effective planning, design and management helps to community policing that requires all crime prevention practitioners to work in collaboration. According to the literature, specialized group of people, such as elder people or people with disabilities are also more worried about their personal safety while they are using public transportation [4]. Derived from theories such as Newman's defensible space, design is directly related to levels of crime and feelings of insecurity that effect of environmental changes on people's fear of travelling [5]. There are some arguments that fear of crime represents a form of gender inequality within the public transportation system [6] and public transportation studies may help to understand the security problems to address users concerns [7].

Perceived safety and security are defined as the assessments of easier accessibility and mostly believed that some measurements have been developed for perceived accessibility in public transport by emphasizing its importance to bring together all forces for sustainable transportation system [8]. Crowe criticizes that criminal acts are concentrated in particular areas of the city and they also developed social disorganization theory based on their conclusions that environmental features of public spaces determine crime rates rather than the characteristics of residents [9]. Barker has proven that crime does not occur randomly in time and space. They can be identified through spatial analysis of where people take their everyday activities. Particularly, some of these locations can generate crime where people gather which create opportunities for offenders such as shopping centres or transit stations where people are vulnerable to victimization [10]. Considering the men, women's concerns about safety influence their travel habits where they avoid using specific transit routes particularly night time because they believe that they may be victimised during their journey [11]. Female victimization is usually higher than men depending on their vulnerability for crime is higher than men. Particularly, anti-social behaviours including physical or verbal harassment have an effect on their feelings of vulnerability [12].

Public transport is a particular public place where passengers move within the specific areas and rules regulating social interactions [13]. Passengers also have varied profile in terms of age, gender, ethnicity etc. however they interact in the same public places through their journey. They sometimes feel isolated and vulnerable to crime depending on environmental and physical features. Previous studies have also contributed to knowledge about differences in fear of crime and perceived safety depending on the personal features. In addition, feelings of safety can also differ depending on socio-economic status, higher income and education [14]. However, detailed analysis of public transportation areas and related environmental features are rarely discussed.

Studies have also proved that routine users feel safer in public transport overall. Because infrequent users are not mostly familiar with these places and use facilities from time to time that make them feel unsafe. Besides, feelings of insecurity also vary depending on the time of day or the day of the week. Although isolation is one of the main factors that increase feelings of insecurity, it may sometimes arise in crowded and unorganized environments, as well [15]. Poor environmental features and maintenance usually increase the anxiety of users 
depending on their age, gender and past experiences. Poorly designed and maintained spaces may increase passengers' fear of crime where they look difficult to escape and people can observe around. However, open public areas can also impact feelings of insecurity, where they are neglected and poorly lit [16]. Since the ability to see and be seen is crucial for increasing perceived safety, poorly lit environments scare passengers, particularly women, elderly and people with disability [17]. Besides, anti-social behaviours and criminal acts also affect passengers perceived safety and can be threatening for people affected by it [18].

Crime prevention includes human behaviour and learning theory as much as environmental design. In this respect, crime prevention should be involved in activities that would reduce crime and anti-social behaviour before it is committed [19]. Crime prevention through design approach includes many aspects that are closely related to each other. According to Greenberg and Firestone crime prevention concept also refers to the human psychology and past experiences in addition to the environmental issues. Therefore, design against crime approach should also cover user-centred and socially responsive solutions [20]. Shaw and McKay introduced proactive methodology that is called behavioural-based design. This concept is beyond of natural surveillance, access control and territorial reinforcement, which argue that its greatest limitation is inability to adapt to behavioural change [21]. Behavioural-based design is a strategic design approach that looks at the predictable ways in which people interact with a given environment, then factors that interaction into the design when developing the most appropriate physical settings for inducing desired behaviour [22]. Design must cover whole system in order to achieve better solutions [23]. In other words, it should also be seen as a process, which applies to all kinds of crime prevention, considering design perspectives and environmental approaches [24].

\section{DEFINITION OF THE CASE STUDY AREA: RAILWAY SYSTEMS IN IZMIR}

Izmir is the third largest city of Turkey located in the middle of the Aegean Region and public transportation within the city is under the authority and responsibility of Izmir Greater Metropolitan Municipality. Izmir subway is one of the 5 subway networks in Turkey and it is $20 \mathrm{~km}$. It is the 4th largest subway network that provides service with 17 access points and 17 stations. The early strategic plans for Izmir subway were initiated in 1989 and Izmir subway reached to 14 stations on the east and west axis of the city with $15.5 \mathrm{~km}$ line length. In 2014, the number of stations increased to 17 and approximately 200,000 passengers were transported per day as given in the Metro Strategic Plan data [25].

Bus-ferry-railway public transportation services are well integrated in the city. These transportation systems consist of two types of rail: subway and suburban trains (Fig. 1). Suburban Train is the only one railway transportation system along the suburban areas around Izmir and this line is in the north-centre-south direction of the region that is $110 \mathrm{~km}$ in length. There are a total of 38 stations along the line.

The transfer stations where these two railway systems intersect are Halkapınar, Hilal and Konak stations where they both have environmental features, which may increase fear of crime for each level of the journey. Therefore, field studies have been carried out at three major transportation nodes selected on intersection points of subway and suburban trains (Fig. 2).

Transfer to the public transport hub Halkapınar and Hilal and Konak stations (red pointed) which are directly connected to the ferry, bus, minibus, taxi and city centre have been determined as a case study (Fig. 2). The existence of different user profiles, product and system diversity at these intersection points with different transportation networks demonstrate an evidence of the case study area. 
The case study selection criteria for these three transportation nodes are determined as follows:

- Halkapinar and Hilal Stations are the only two points intersecting the north-south development axis of the city and the east-west development axis.

- Izmir Subway is a type of transportation that is developing and still being built in the city, which includes open and closed route and station systems which has a line passing through the city centre.

- There are different land uses such as Airport, residential area and industrial area along the subway line that connects the regions with highest population density.

- User profiles vary in many aspects including; age, gender, socio-economic features, etc.

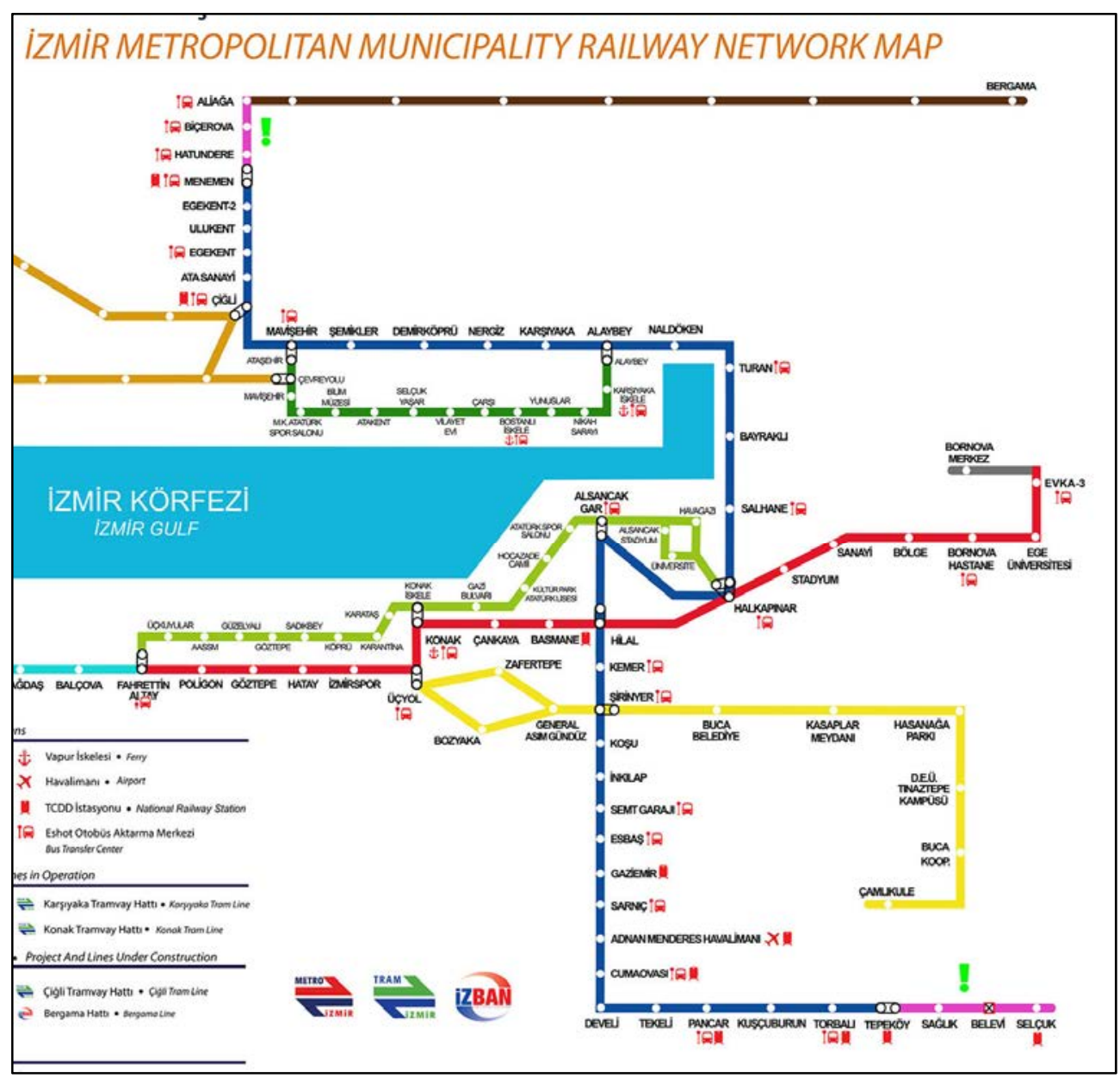

Figure 1: Izmir Metropolitan Municipality Railway Network Map. (Source: http://www.izmirmetro.com.tr.) 


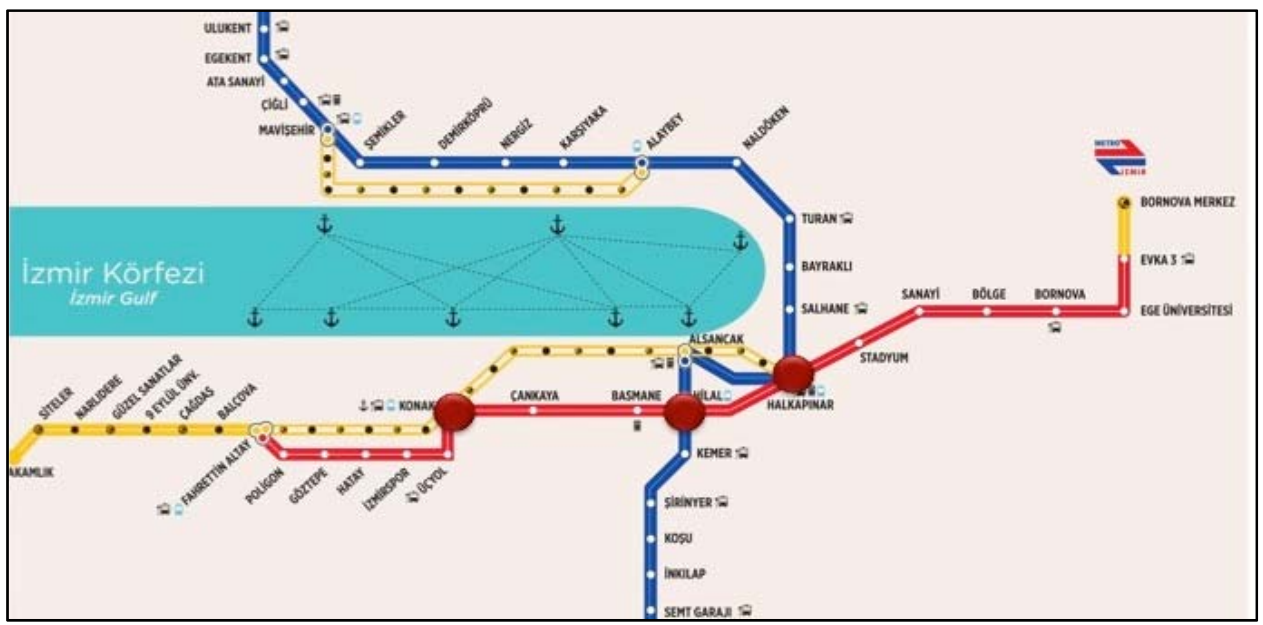

Figure 2: Transfer stations of Izmir Greater Metropolitan Area Railway System. (Source: http://www.izmirmetro.com.tr.)

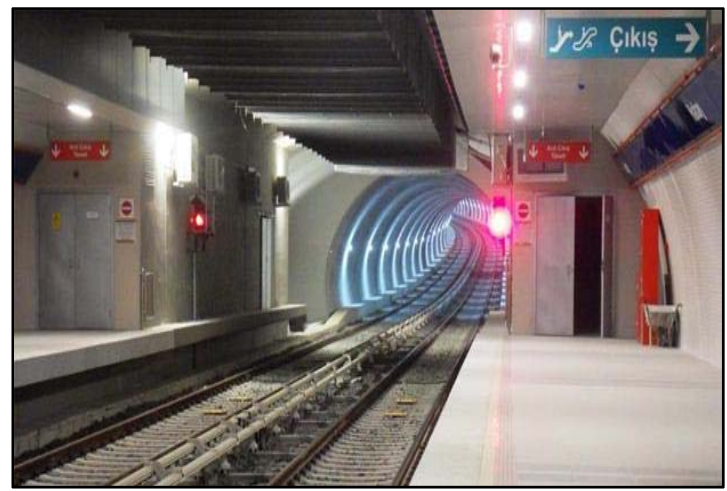

(a)

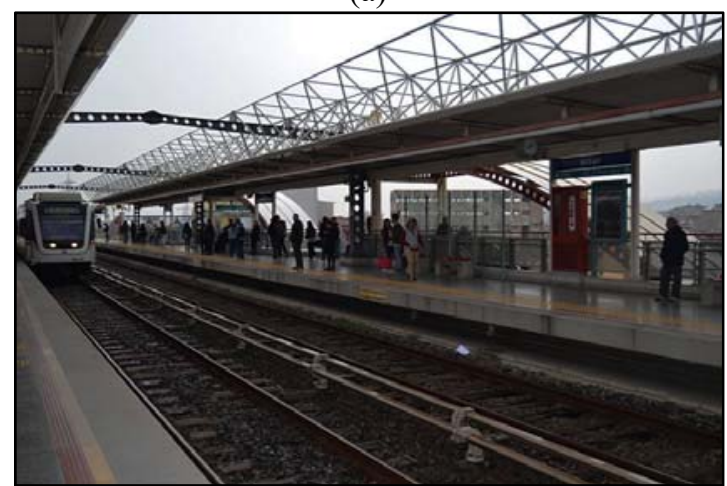

(b)

Figure 3: Transfer station views of Izmir Greater Metropolitan Area Railway. (Source: www.izmirmetro.com.tr.) 
Through the research process, necessary spatial notes were taken and visual data were obtained. Within the scope of these field studies the data obtained from the field study are analysed and explained in detail in the following section. The methods of this particular study are mainly based on systematic observations and user transportation survey, which includes the whole journey issues.

The study includes the results of the survey derived from the answers of 351 respondents in order to analyse their public transportation habits and feelings of insecurity through their whole journey in İzmir subway. This paper also based on specific data obtained from the related stations of İzmir subway in addition to the systematic observations.

\section{FINDINGS AND EVALUATION OF THE RESULTS}

The key findings of this particular study derived from the user survey and systematic observations are submitted in Table 1.

The user survey includes questions such as how respondents behave when they feel insecure in the transit environment. In order to understand how perceived safety has an effect on their travelling habits, they were asked whether they change their transport routines such as travel time, period, etc. when they feel insecure. For instance, $73 \%$ of respondents prefer using public transportation in specific time period when crime or anti-social behaviours are less likely to occur in order to protect themselves from being victims. As another remarkable result, the location of the station and its related surroundings are also crucial for the passengers. In other words, most of the passengers explained that they could only prefer the specific station when they believe that the location is safe and secure for them to use (Table 1).

Usage frequency and passenger density have an effect upon perceived safety and feelings of insecurity (Table 2). Women or elder people usually avoid travelling in particular hours where the most serious crimes and offences are likely to occur. In this case, these particular user groups mostly feel that their movements need to be restricted for their security. Because most unwanted sexual or anti-social criminal behaviours occur during night times, which decreases personal safety. They also prefer avoiding transportation lines and related environment such as stations that are mostly defined as insecure or neglected.

Based on the results derived from the questionnaire design and safe public transportation relationship are mostly related with the environmental and physical features of the whole journey approach. According to the results, respondents feel more secure in particular spots in which better-lit and designed areas in addition to the security precautions. On the contrary, they feel insecure $(53 \%)$ when physical interactions and security precautions cannot be completely controlled because of overcrowded etc. in some cases, such as entrances and exits of stations with their surroundings (Table 3).

Table 1: Factors that affect perceived safety.

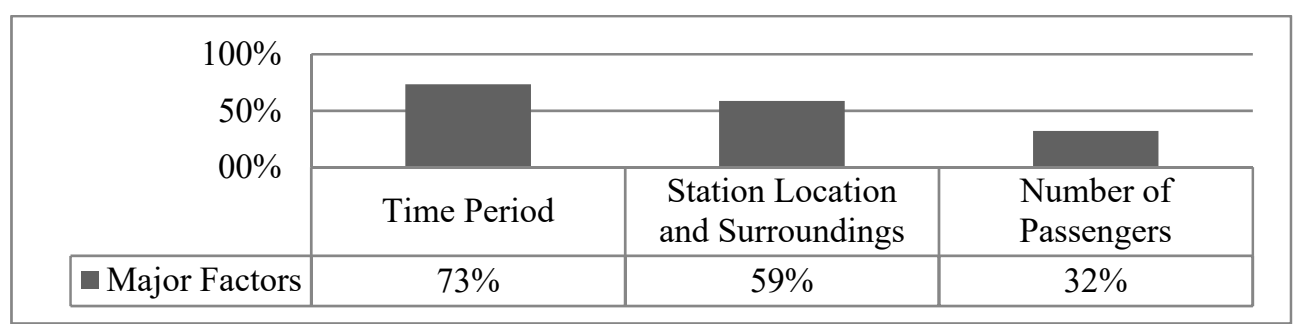


Table 2: Usage frequency and feelings of insecurity.

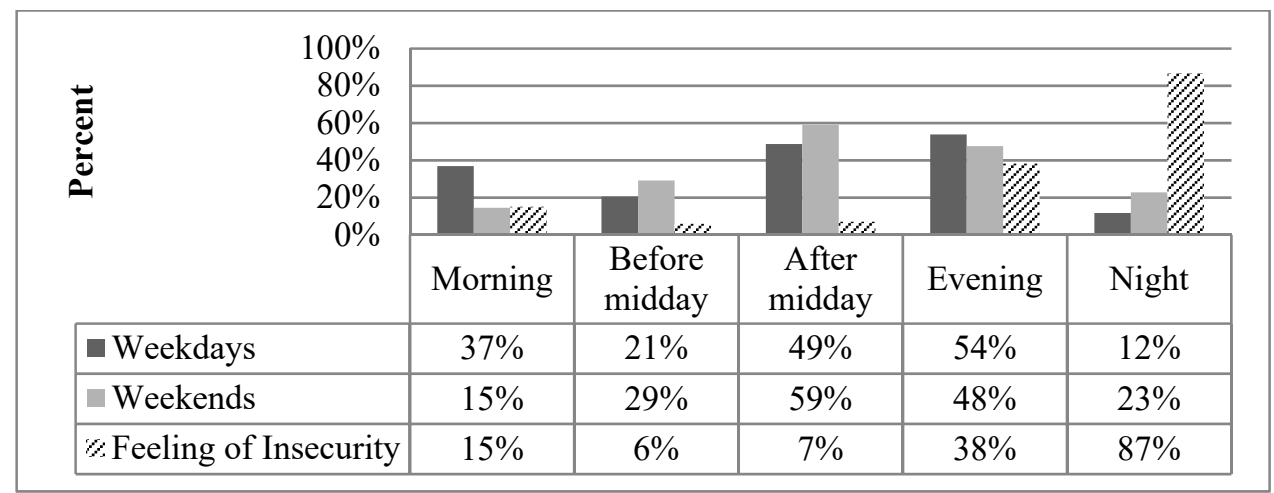

Table 3: Related spaces of whole journey approach.

\begin{tabular}{|c|c|c|}
\hline $\begin{array}{c}\text { Related spaces of whole journey } \\
\text { approach }\end{array}$ & Response percentage & Response count \\
\hline Entrances and exits of stations & $53.0 \%$ & 186 \\
\hline Staircases and escalators & $31.6 \%$ & 111 \\
\hline Subway platforms & $31.3 \%$ & 110 \\
\hline Interiors of subway cars & $36.2 \%$ & 127 \\
\hline & Answered question & $\mathbf{3 5 1}$ \\
\hline & Rate of return & $\mathbf{1 0 0 \%}$ \\
\hline
\end{tabular}

Table 4: Design and safe public transportation relationship.

\begin{tabular}{|l|c|}
\hline $\begin{array}{c}\text { Necessary components according to their contributions to } \\
\text { the security of subway and nearby areas }\end{array}$ & Average score \\
\hline Bicycle and motorcycle parks & 3.73 \\
\hline Escalator & 4.21 \\
\hline Lift & 4.26 \\
\hline Disable/baby stroller access & 4.54 \\
\hline Additional security staff & 4.27 \\
\hline Additional security products & 4.18 \\
\hline Additional safety precautions & 4.34 \\
\hline Additional activities & 3.86 \\
\hline Signing and emergency evacuation exits & 4.33 \\
\hline Safer railway station for all passengers & 4.40 \\
\hline Safer subway car usage for all passengers & 4.40 \\
\hline Answered question & $\mathbf{3 5 1}$ \\
\hline Rate of return & $\mathbf{1 0 0 \%}$ \\
\hline
\end{tabular}


Table 5: Type of existing components.

\begin{tabular}{|l|c|}
\hline Type of existing components & Average score \\
\hline Design features & $\mathbf{2 . 7 6}$ \\
\hline Security precautions & $\mathbf{2 . 5 8}$ \\
\hline Social and commercial activity areas & $\mathbf{2 . 1 5}$ \\
\hline Routine passengers & $\mathbf{3 . 5 4}$ \\
\hline Wayfinding and signage & $\mathbf{3 . 1 3}$ \\
\hline
\end{tabular}

*According to the 1-5 Likert scale scores.

Certain amount of users who reported feeling unsafe considers that changing routines is an option and time-based avoidance is one of the most frequent adaptive behaviour for the users who reported feeling unsafe avoid certain times.

Users who declared feeling unsafe avoid particular lines and places or changes means of transport in order to increase their personal safety. They also believe that necessary components such as additional security products, better signing and functions (additional social activities which keeps the neglected areas busy and create visibility) may also contribute to the security and increase safety of subway and nearby areas (Table 4).

According to the study, design (environmental, signage, lighting, etc.) and management (social and commercial activity areas through routine passengers) issues in subway systems and their effects on perceived safety are remarkable (Table 5). Increasing safety issues and precautions through design can also affect public transport passenger' mobility. Particularly, avoidance may increase for the whole journey approach if design and management issues for public transportation is not successfully planned and/or applied for the long-term success and sustainable development.

\section{CONCLUSION}

Since crime prevention through design studies uses planning, design and place management strategies to reduce the likelihood of crime in time and space, community interaction and collaborative studies among professions are crucial. It is obvious that reducing insecurity through planning and design measures for public transportation must be considered for the whole journey approach. It must also be based on the local situations for each particular city since each city has its unique nature and dynamics.

According to the results of this particular study, actual or perceived danger also generates avoidance behaviours and changes transportation habits may affect users fear of crime. Individual characteristics may also affect passengers' fear and avoidance and fear of crime may increase with age, gender, disability, etc. However, usage frequency may decrease avoidance because passengers who are more vulnerable to crime or anti-social behaviour can be more familiar with the public transport environment, which increase their perceived safety.

Consequently, being aware of the potential crime risks of a location and considering the effect of potential changes to the built environments is crucial before deciding on planning and design solutions for sustainable public transportation development. In order to increase permanent usage for all passengers, additional design and management of the public transport should be considered according to the spatial and organizational features for increasing perceived safety and also for developing safer and sustainable transportation for cities. 


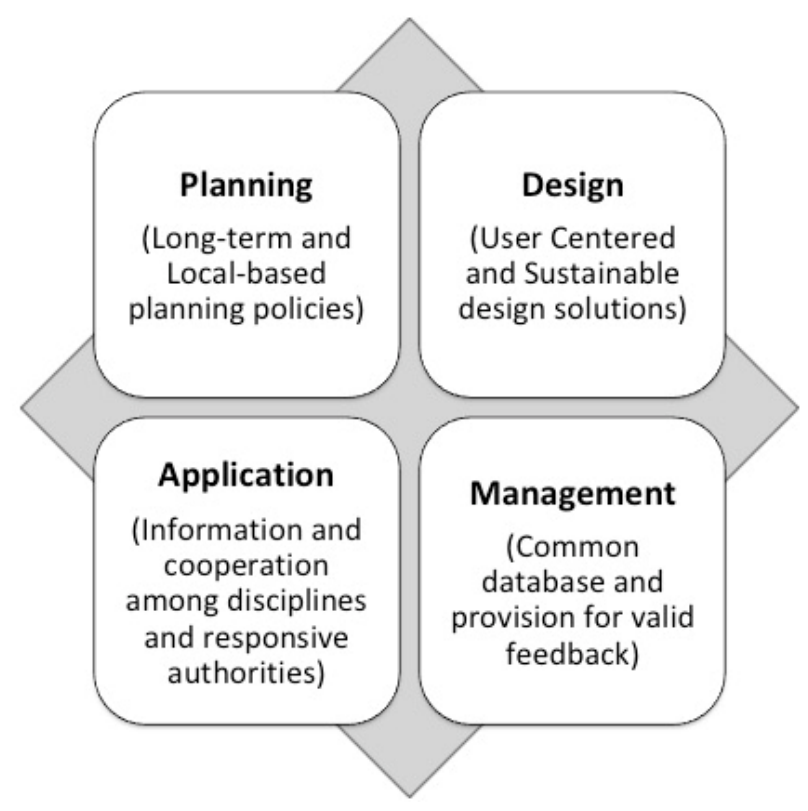

Figure 4: Sustainable public transportation components.

\section{ACKNOWLEDGEMENT}

This study is a part of the scientific research project funded by Izmir University of Economics.

\section{REFERENCES}

[1] Allford, V., Crime and spaces in the inner city. Crime Design Studies, 2, p. 53, 1996.

[2] Altman, I. \& Cheemers, M.M., Culture and Environment, Brooks/Cole: Monterey, CA, 1986.

[3] Cozens, P., A virtual reality approach to personal safety and the design of built environment facilities. Conference Proceedings of the 18th ARCOM Conference (Association of Researchers in Construction Management), pp. 461-473, 2002.

[4] Cozens, P.M., Hillier, D. \& Prescott, G., Criminogenic associations and British housing design. International Journal of Planning, 7, 2002.

[5] Appleyard, D., Livable Streets, University of California Press: Berkeley, 1981.

[6] Cohen, L.E. \& Felson, M., Social change and crime rate trends: a routine activity approach. American Sociological Review, 44, pp. 588-608, 1979. DOI: $10.2307 / 2094589$.

[7] Beck, I. \& Wood, D., Cognitive transformation of information from urban geographic fields to mental maps. Environment and Behavior, 8(2), pp. 199-237, 1976. DOI: $10.1177 / 001391657682003$.

[8] Blöbaum, A. \& Hunecke, M., Perceived danger in urban public space - the impacts of physical features and personal factors. Environment and Behaviour, 37(4), pp. 465486, 2005. DOI: 10.1177/0013916504269643.

[9] Crowe, T.D., Crime Prevention through Environmental Design: Applications of Architectural Design and Space Management Concepts, Butterworth-Heinemann: London, 1991. 
[10] Barker, R.G., Ecological Psychology: Concepts and Methods for Studying the Environment of Human Behaviour, Stanford University Press: California, 1968.

[11] Coupland, A., Reclaiming the City-Mixed Use Development, University of Westminster: London, UK., 1997.

[12] Ferraro, K.F., Women's fear of victimization: shadow of sexual assault? Social Forces, 75, pp. 667-690, 1996. DOI: 10.1093/sf/75.2.667.

[13] Fisher, B.S. \& Sloan, J.J., Unravelling the fear of victimization among college women: is the "shadow of sexual assault hypothesis" supported? Justice Quarterly, 20, 633655, 2003. DOI: 10.1080/07418820300095641.

[14] Cook, T.D., Fremming, J. \& Tyler, T., Criminal victimization of the elderly: validating the criminal victimization, with special focus on women and the elderly. Victimology, 10, 325-358, 1981.

[15] Mahmoud, S. \& Currie G., The Relative Priority of Personal Safety Concerns for Young People on Public Transport-Nature of Concerns and User Priorities for Action, Australasian Transport Research Forum: Canberra, 2010.

[16] Loukaitou-Sideris, A., Bornstein, A., Fink, C., Samuels, L. \& Germai, S., How to Ease Womens Fear of Transportation Environments: Case Studies and Best Practices, Mineta Transportation Institute, 2009.

[17] Bell, P.A., Fisher, J.D. \& Loomis, R.J., Environmental Psychology, Saunders: Philadelphia, 1978.

[18] Brantingham, P., Brantingham, P. \& Wong, P., How public transit feeds private crime: notes on the vancouver experience. Security Journal, 2(2), 91-95, 1991.

[19] Mawby, R. \& Gill, M., Crime Victims: Needs, Services and the Voluntary Sector, Routledge: London, UK, 1987.

[20] Greenberg, C. \& Firestone, I., Compensatory responses to crowding: effects of personal space intrusion and privacy reduction. Journal of Personality and Social Psychology, 35(9), pp. 637-644, 1977.

[21] Shaw, C. \& McKay, H., Juvenile Delinquency and Urban Areas, Criminological Theory: Past to Present, Los Angeles, CA, pp. 65-70, 1999.

[22] Bentley, I., Responsive Environments, Architectural Press: London, 1985.

[23] Bailly, A.S., La Perception De L'espace Urbain, Durves, 1977.

[24] Cassidy, T., Environmental Design, Environmental Psychology, Behaviour and Experience in Context, Psychology Press: UK, 1997.

[25] Metro Strategic Plan. Online. www.izmirmetro.com.tr, 2015. 